Journal of Engineering and Applied Sciences 15 (1): 74-80, 2020

ISSN: 1816-949X

(C) Medwell Journals, 2020

\title{
Optimization of Resource Consumption When using Vehicle Transmissions at Low Temperatures
}

\author{
Aleksey Dolgushin, Dmitriy Voronin and Oleg Mamonov \\ Federal State Budgetary Educational Establishment of Higher Education, \\ Novosibirsk State Agrarian University, Dobroluybov Street, 160, Novosibirsk, Russia
}

\begin{abstract}
This research details the approach to justify optimum thermal conditions for a vehicle transmission unit. This approach is based on the integrated criterion which comprises aggregated energy expenditures to warm up a transmission reduction gear and to overcome forces of mechanical and hydraulic friction inside its components. Thermal working conditions of a unit shall be considered optimum when energy expenditures are the lowest. Justification and development of technologies to provide optimum thermal conditions of a unit shall be based on comparison of optimum temperature values and temperature values of transmission oil stabilization. If optimum temperature exceeds stabilization temperature, then additional heat sources shall be used if it is lower then heat shall be transferred to other units. Analysis of optimum thermal conditions of the KAMAZ transmission shows that the transmission unit has an excessive thermal potential. Optimum temperature exceeds stabilization temperature by $5 \mathrm{~K}$, so, excessive thermal energy must be transferred.
\end{abstract}

Key words: Transmission, thermal conditions, preheating, energy expenditures, optimum temperature, stabilization

\section{INTRODUCTION}

Automobile transport makes an important part of a transport system of any country. The way it works significantly affects the time and costs of cargo and passenger delivery. One of the main features of automobile transport is that it is used all year round. Many countries have to use automobile transport in subzero weather conditions during some part of the year.

In Russia, the share of cargoes transported in months with daily mean temperatures below zero is $20-40 \%$ of the annual amount, depending on the region (Izmailov, 2007). Severe working environment puts high demands on reliability and performance of all units, quality of combustibles and lubricants and other resources.

Experience of using production vehicles in rough environments proves significant decrease in their efficiency and increase in consumption of resources for maintenance and repair. One of the main reasons of poor working efficiency of vehicles is violation of thermal working conditions of systems and units (Alvarez and Weilenmann, 2012; Reiter and Kockelman, 2016). Based on the research findings (Weilenmann et al., 2009, Anisimov et al., 2017) using vehicles in sub zero conditions increases engine fuel consumption by 7-9\%. Higher engine fuel consumption leads to higher pollutant emissions which significantly worsens ecological conditions in cold regions. Studies show an apparent increase in $\mathrm{CO}_{2}$ emissions (Frank, 2010). According to research data (Chainikov et al., 2016) when ambient temperature reaches $20^{\circ} \mathrm{C}$ below zero, $\mathrm{CO}_{2}$ emissions from a moving vehicle increase by $5 \%$ oreover, engine warm-up causes additional emissions of other pollutants (Merkisz et al., 2011).

Transmission units degrade fuel efficiency of an engine as well. Intensive heat exchange between a gearbox and drive axles and environment while driving or stopping the vehicle as well as in the process of storing, causes a significant decrease in temperature and viscosity of transmission oils. Testing a KAMAZ truck vehicle at the ambient temperature of $30^{\circ} \mathrm{C}$ below zero shows that the temperature of the gearbox reaches approx. About $30-35^{\circ} \mathrm{C}$ while the temperature of intermediate and rear axles generally remains below zero (Dolgushin et al., 2015). Operation at such oil temperatures makes the life of transmission units three times (Korneyev et al., 2017) shorter and reduces efficiency by 30-40\% (Buzin, 2011). The main reason of low transmission efficiency at low temperatures is the need to overcome forces of mechanical and hydraulic friction inside a transmission reduction gear. According to the given data (Wang et al., 2015), transmission units power loss is mainly connected to mechanical friction in gears engaged in torque transfer as well as hydraulic losses when splashing and stirring motor oil. Besides, the research (Liebrecht et al., 2015) indicates the need to consider power losses when overcoming friction torque in roller bearings.

Corresponding Author: Aleksey Dolgushin, Federal State Budgetary Educational Establishment of Higher Education, Novosibirsk State Agrarian University, Dobroluybov Street, 160, Novosibirsk, Russia 
Here, we can make a conclusion that the lubricant oil temperature determines effective functioning of all transmission units of a vehicle. Given that engine fuel gets more expensive and environmental legislation increases its pressure, many developed countries have to face new challenges to provide and maintain optimum temperature of transmission units.

One of the ways to resolve these challenges is to use various transmission reduction gear preheat systems. The following methods are discussed here: transmission warm-up prior to movement and autonomous heating during vehicle's movement. The research Hawley et al. (2010) studies effectiveness of transmission oil warm-up using an $495 \mathrm{~W}$ electric heater. According to the findings, engine fuel waste at the ambient temperature of $7^{\circ} \mathrm{C}$ below zero has been $15 \%$. The research (Iliev and Lohse-Busch, 2018) proves advantages of using engine exhaust heat as energy for transmission warm-up as this method does not affect power characteristics and fuel efficiency of a vehicle.

It is clear that use of any ways and means of transmission warm-up shall be based on some economical criteria. While estimating transmission warm-up efficiency, it is important to compare the achieved technical and economical effects with the costs of the suggested method. Studies (Gillot et al., 2015) show that warm-up of a vehicle's gearbox in a temperature range of $23-90^{\circ} \mathrm{C}$ reduces fuel consumption by $1.7 \%$. By correlating warm-up costs to fuel savings, the researchers conclude that warming up the gearbox above $23^{\circ} \mathrm{C}$ makes no economic sense. Thus, justification of optimum thermal conditions of transmission units in terms of resource consumption becomes the number one problem at present.

\section{MATERIALS AND METHODS}

In the context of resource saving, optimum thermal conditions of transmission units must be looked at comprehensively, taking into consideration resource consumption to provide optimum thermal conditions and resource consumption to overcome friction torque in units under these conditions. Formalizing the task of identifying optimum thermal conditions of transmission units shall come down to identifying and minimizing total resource expenditures for operation of units. Minimum expenditures correspond to optimum thermal conditions. Various external heat sources can be used to heat transmission units. Consumption of energy resources, used to provide and maintain the given thermal conditions for a transmission reduction gear can be represented as follows:

$$
\mathrm{Q}_{\mathrm{w}}=\mathrm{At}^{\mathrm{m}}, \mathrm{J}
$$

Where:

A : Coefficient of a change rate of unit's thermal conditions $(\mathrm{J} / \mathrm{h})$

$\mathrm{t}$ : The time needed for warm-up (h)

$\mathrm{m}$ : Coefficient that determines behaviour of thermal conditions

Apart from using external heat sources, warm-up of transmission units is possible through mechanical-tothermal energy conversion. In this case, mechanical and hydraulic friction inside a unit will be used as a heat source. Energy resource expenditures to overcome a friction torque in a unit can be determined by the following equation:

$$
Q_{\mathrm{f}}=\frac{B}{t^{\mathrm{n},}} J
$$

Where:

B : Coefficient of a change rate of a friction torque in a unit $(\mathrm{J} / \mathrm{h})$

$\mathrm{n}$ : Coefficient which determines behaviour of a friction torque in a unit

The main goal of optimization of transmission reduction gear thermal conditions is to ensure minimum total expenditures of thermal energy $Q_{w}$ И $Q_{f}$, i.e:

$$
\mathrm{Q}_{\mathrm{w}}+\mathrm{Q}_{\mathrm{f}} \rightarrow \min
$$

Mathematically, the Eq. 3 can be represented as follows:

$$
\left(\mathrm{Q}_{\mathrm{w}}\right)^{\prime}+\left(\mathrm{Q}_{\mathrm{f}}\right)^{\prime}=0
$$

Derivatives of resource expenditures $Q_{w}$ and $Q_{f}$ can be determined by the following equation:

$$
\begin{aligned}
& \left(A t^{m}\right)^{\prime}=A m t^{m-1} \\
& \left(\frac{B}{t^{n}}\right)^{\prime}=-\frac{B n}{t^{n+1}}
\end{aligned}
$$

If we plug Eq. 5 and 6 into the Eq. 4 and formulate the t-value, we will get an expression to define time needed to reach optimum thermal conditions:

$$
\begin{gathered}
t_{o p t}=\sqrt[m+n]{\frac{B n}{A m}, s} \\
t_{o p t}=\left(\frac{B n}{A m}\right)^{(m+n)^{-1}}, s
\end{gathered}
$$


This dependence (Eq. 8) does not reflect actual interaction of reduction gears with environment but only determines time interval to achieve the given goal. In terms of resource saving, the given task shall be resolved within defined temperature ranges both for environment and a transmission unit. This limitation can be represented as follows:

$$
\mathrm{T}_{\mathrm{amb}} \leq \mathrm{T}_{\text {oper }} \leq \mathrm{T}_{\mu}
$$

Where:

$\mathrm{T}_{\text {oper }} \quad$ : The temperature of a given unit (K)

$\mathrm{T}_{\mathrm{amb}}$ and $\mathrm{T}_{\mu}$ : Minimum and maximum temperature levels for vehicle's transmission reduction gears $(\mathrm{K})$

By minimum temperature level of transmission reduction gears $T_{\text {amb }}$ we mean ambient temperature $T_{\text {amb }}$. This temperature corresponds to the maximum viscosity of transmission oil in in the temperature range covered. By the maximum transmission temperature $T_{\mu}$ we mean temperature at which lubrication oil viscosity prevents wear and tear of gears and bearings under subgrade stresses. Besides, maximum reduction gear temperature allows for minimum energy loss on friction and maximum efficiency.

While addressing this issue, it is necessary to take the following into consideration. Operation of vehicles at low temperatures puts some certain requirements to transmission oil in terms of the upper and lower viscosity points. Maximum permissible viscosity is defined by the viscosity at the minimum operation temperature that allows for a seamless start of a vehicle without causing any damage to gears and bearings and without oil preheat in transmission units.

In light of the above, let's discuss oil viscosity behaviour when thermal conditions of a specific transmission unit is changed (Fig. 1). From the point of preparation to warm-up, the function $\mu=\mathrm{f}(\mathrm{T})$ can be divided in two zones: Zone I and Zone II. The Zone I demands pre-heating of transmission units from an external heat source up to temperature $T_{1}$. Transmission operation at the oil temperature lower than $T_{1}$ causes reduction gear failure.

$\mathrm{T}_{\mathrm{amb}}, \mathrm{T}_{1}, \mathrm{~T}_{\mu}$ are ambient temperature, final pre-heat temperature and final warm-up temperature respectively, ${ }^{\circ} \mathrm{K}$; I, II are rational decision search zones.

There are two ways to achieve oil temperature $T_{\mu}$ in a reduction gear (Zone II). The first one is to continue warming up the unit from an external heat source. The second way is self-warm-up of a vehicle during movement. Regardless of the selected strategy to prepare transmission reduction gears to warm-up in the Zone II, definition of optimum thermal conditions of units involves the search for the extreme value of a target function:

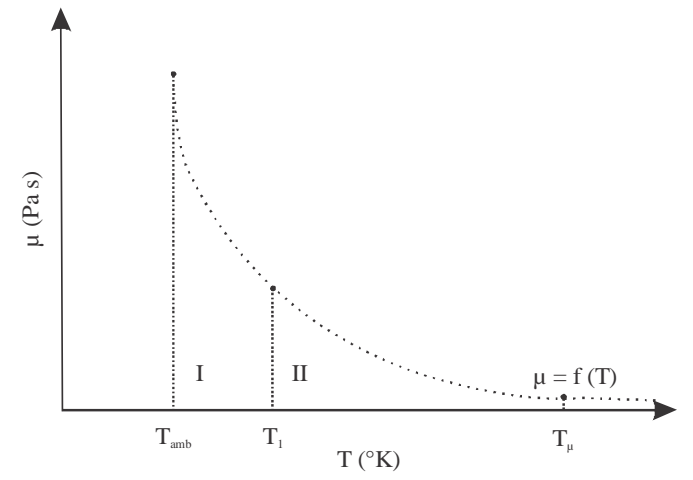

Fig. 1: Lubrication oil viscosity behaviour at transmission reduction gear warm-up

$$
\mathrm{Q}_{\Sigma}=\mathrm{Q}_{\mathrm{w}}+\mathrm{Q}_{\mathrm{f}} \rightarrow \min
$$

where, $\mathrm{Q}_{\Sigma}=$ Total expenditures of energy resources necessary for a transmission unit to operate, JK. The need for energy resources to warm up a transmission reduction gear up to the given temperature, taking into account all limitations (Eq. 9) can be represented as follows:

$$
\mathrm{Q}_{\mathrm{w}}=\mathrm{Q}_{\text {costs }}\left(\mathrm{T}_{\text {oper }}-\mathrm{T}_{\text {env }}\right), \mathrm{J}
$$

Where:

$\mathrm{Q}_{\text {costs }}$ : Specific costs of energy aimed at provision of transmission unit's thermal conditions $(\mathrm{J} / \mathrm{K})$

$\mathrm{T}_{\text {oper }}$ : The temperature of a given unit (K)

$\mathrm{T}_{\text {env }}$ : Ambient temperature (K)

Reduction gear friction torque depends on viscosity temperature properties of lubricants and is in exponential relation with them. The higher the temperature of a lubricant, the lower its viscosity and friction torque are:

$$
\mathrm{M}_{\mathrm{f}}=\mathrm{M}_{0} \mathrm{e}^{-\mu\left(\mathrm{T}_{\mu}-\mathrm{T}_{\text {oper }}\right)}, \mathrm{Nm}
$$

Where:

$\mathrm{M}_{0}$ : The friction torque at a maximum permissible temperature of lubricant oil (Nm)

$\mu \quad$ : Coefficient of friction torque reduction

$\mathrm{T}_{\mu}$ : Maximum permissible temperature of lubricant oil (K)

Thus, thermal energy expenditures to overcome a friction torque $\mathrm{Q}_{\mathrm{f}}$ can be determined by the following equation:

$$
\mathrm{Q}_{\mathrm{f}}=\mathrm{Q}_{0} \mathrm{e}^{-\mu\left(\mathrm{T}_{\text {oper }}-\mathrm{T}_{\mu}\right)}, \mathrm{J}
$$




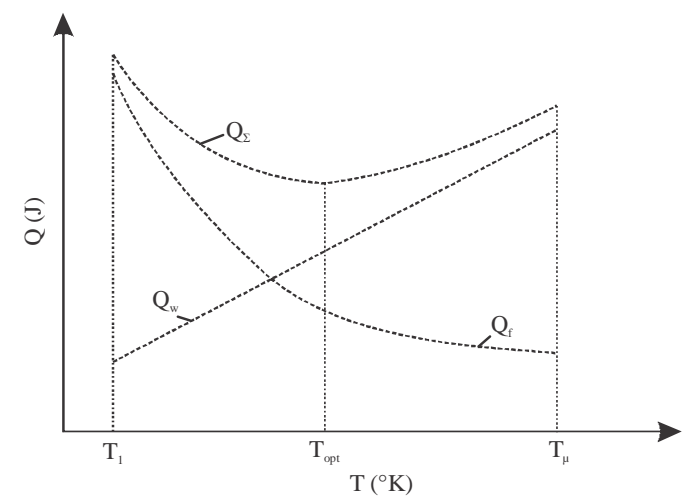

Fig. 2: Determining optimum thermal conditions of a transmission unit

where, $\mathrm{Q}_{0}=$ energy resource expenditures at a maximum permissible temperature of lubricant oil (J). The nature of these dependencies of energy resource expenditures to provide necessary thermal conditions of a transmission unit $\mathrm{Q}_{\mathrm{w}}$ and resource expenditures to overcome a friction torque in a transmission unit $\mathrm{Q}_{\mathrm{f}}$ from the temperature of a transmission unit is determined by Eq. 11 and 13 and represented by Fig. 2. Diagram analysis shows that optimum thermal conditions of a transmission unit corresponds with minimum total resource expenditures. Thus, the task of determining the minimum of a function (Eq. 10) comes down to determining the extremum point of a total heat expenditures function in the temperature range covered.

Handling this task in relation to a specific unit, we assume that optimization of energy expenditures shall be performed in the following temperature range of a reduction gear:

$$
\mathrm{T}_{1} \leq \mathrm{T}_{\text {oper }} \leq \mathrm{T}_{\mu}
$$

First, let's calculate the derivative of the $\mathrm{Q}_{\mathrm{w}}+\mathrm{Q}_{\mathrm{f}}$ sum by the temperature of a transmission reduction gear $\mathrm{T}_{\text {oper: }}$ :

$$
\left(\mathrm{Q}_{\text {costs }}\left(\mathrm{T}_{\text {oper }}-\mathrm{T}_{\text {env }}\right)\right)^{\prime}+\left(\mathrm{Q}_{0} \mathrm{e}^{-\mu}\left(\mathrm{T}_{\text {oper }}-\mathrm{T}_{\mu}\right)\right)=0
$$

From this equation, we can calculate the optimum temperature of a reduction gear $\mathrm{T}_{\mathrm{opt}}$ :

$$
\mathrm{T}_{\mathrm{opt}}=\mathrm{T}_{\mu}-\ln \left|\frac{\mathrm{Q}_{\mathrm{costs}}}{\mu \mathrm{Q}_{0}}\right|^{\frac{1}{\mu}}
$$

Figure 2 analysis shows if the target temperature of a reduction gear is lower than the final warm-up temperature $T_{\text {opt }} \leq T_{1}$, then $T_{1}$ shall be considered the optimum temperature. If the equation is $T_{\text {opt }} \geq T_{\mu}$, then $T_{\mu}$ shall be considered the optimum temperature.

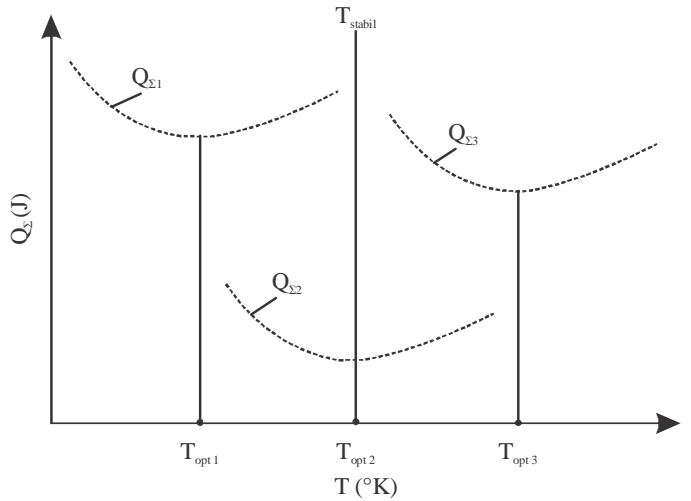

Fig. 3: Possible thermal states of a unit

Graphic and analytic determination of $\mathrm{T}_{\mathrm{opt}}$ is conventional and just points the way to find extreme values for a reduction gear without any restrictions on actual movement conditions and change rate of the reduction gear temperature. It is not unthinkable that the maximum temperature of a reduction gear (stabilization temperature) during movement without speed limitation may reach values beyond the estimated optimum temperature range (Fig. 3).

Diagrams of possible thermal states determine possible optimum values relative to the oil stabilization temperature.

Case 1: $\mathrm{T}_{\mathrm{opt} 1}<\mathrm{T}_{\text {stabil }}$, i.e., the optimum value is reached at the temperature lower than the stabilization temperature of thermal conditions during movement. In this case, there is a need to transfer excessive heat from a unit as minimum heat expenditures can be reached at lower temperatures.

Case 2: $\mathrm{T}_{\text {opt1 }}=\mathrm{T}_{\text {stabil }}$, i.e., the optimum value is reached at the temperature equal to the stabilization temperature of thermal conditions during movement, i.e., the system is in thermal equilibrium.

Case 3: $\mathrm{T}_{\text {opt1 }}>\mathrm{T}_{\text {stabil }}$, i.e., the optimum heat expenditures value is reached at the temperature higher than the stabilization temperature of thermal conditions during movement. In this case, there is a need for additional heating and maintaining thermal conditions at the level of optimum temperature values.

\section{RESULTS AND DISCUSSION}

Let's consider an optimization strategy for thermal conditions of transmission units by looking at a mechanical speed-change gearbox of a KAMAZ truck. At the first stage we measured the temperature of the transmission oil in the case while the truck was moving. The truck was moving smoothly on a level road at the 


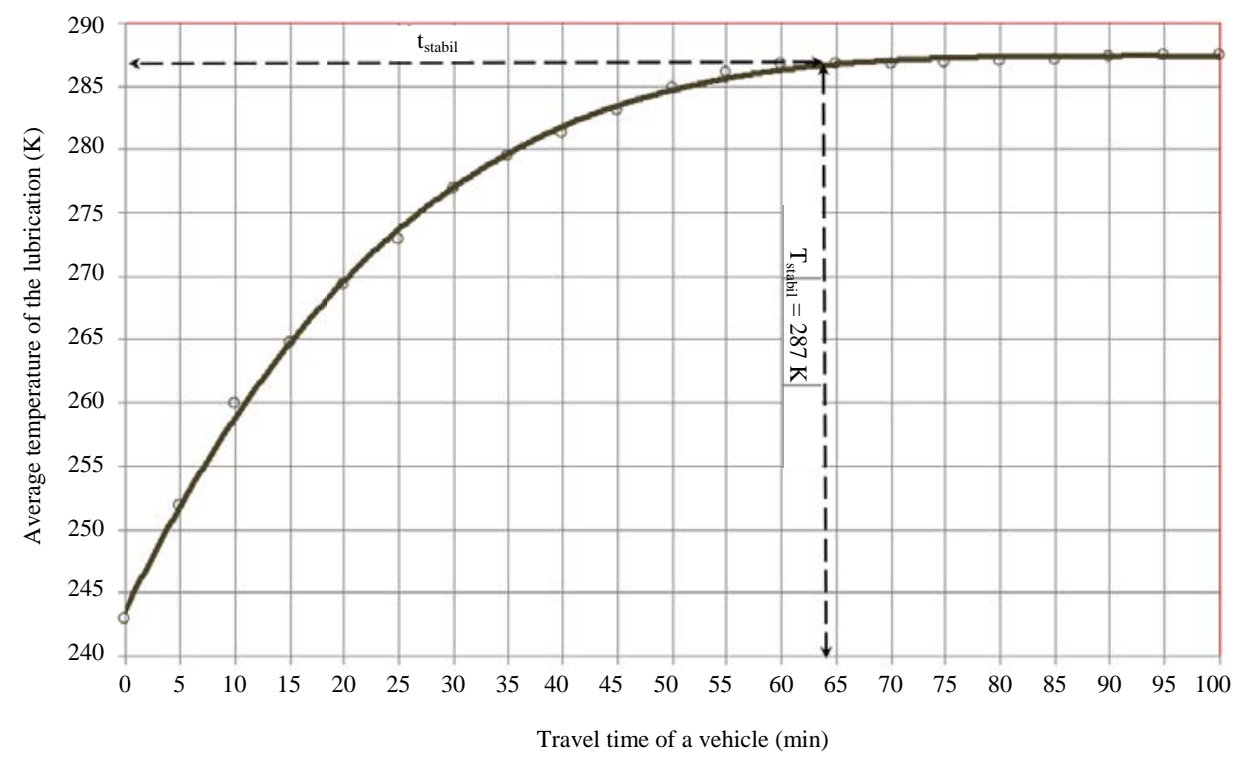

Fig. 4: Oil warming-up rate in the gearbox

speed of $30 \mathrm{~km} / \mathrm{h}$ at the ambient temperature of $243 \mathrm{~K}$ $30^{\circ} \mathrm{C}$. Wind velocity was close to $0 \mathrm{~m} / \mathrm{sec}$. Prior to movement the truck's engine was pre-heated using a starting heater. To register the temperature, we used a heat sensor installed in a drain plug and connected to a PC-based measuring system. Observed correlation of the oil temperature to the travel time is represented in Fig. 4.

Diagram data analysis shows that the transmission oil temperature in the gearbox case changes exponentially. At the first stage of warming-up, the temperature changes faster due to high viscosity of the oil. As viscosity gets lower, the warm-up speed slows down. According to this diagram, the oil temperature in the gearbox reached stability at $287 \mathrm{~K}$ which means reaching thermal balance with the environment. The gearbox reaches given thermal conditions in 60-65 min.

At the next stage, we performed calculation and experimental estimation of the oil temperature in the given reduction gear following the mentioned energy approach. Estimation of energy expenditures to warm up the gearbox was based upon data on the average mean heat capacity and weight of all components. To estimate energy expenditures to overcome internal friction forces during operation of the unit, we determined functional correlation of efficiency factors in spur and bevel gears, bearings and the oil bath to the oil temperature. Calculation is based on viscosity-temperature properties of the oil used in the gearbox. Functional dependencies of energy expenditures on the temperature are represented by Fig. 5.

Detailed analysis of dependencies on Fig. 5 shows that energy expenditures to warm up the gearbox are linearly dependent and can reach up to $4500 \mathrm{~kJ}$ in defined conditions. Amount of these energy expenditures depends on design features of the unit to be heated and specifications of a heater. We used a $8 \mathrm{~kW}$ heater with the heat transfer efficiency factor $0.5 \%$.

Energy expenditures to overcome resistance forces in the unit does not change linearly as they mainly depend on the transmission oil viscosity. Amount of these expenditures is conditioned by design and operation parameters of the gearbox as well as viscosity-temperature properties of the oil. Under defined conditions, energy expenditures $Q_{s}$ change within the range of $1400-2000 \mathrm{~kJ}$.

Tracing dependencies of total energy expenditures for the unit to operate on the ambient temperature shows that optimum thermal conditions in terms of minimization of energy expenditures are 28-282 K. Therefore, it is necessary to maintain a certain oil temperature by using some technical means to ensure effective operation of the gearbox in the given conditions.

Comparison of the stabilization temperature for the unit in question used at the ambient temperature of $243 \mathrm{~K}$ shows that according to the above-mentioned energy approach to energy expenditures optimization, the studied gearbox has an excessive thermal potential. Hence, redistribution of excessive heat from the gearbox to other heat-stressed transmission units can be considered.

In terms of effective operation of vehicle transmissions at low temperatures, it is feasible to consider not only justification and provision of thermal conditions of specific transmission units but also minimization of energy expenditures within the system of transmission units. In addition, some of transmission units may act as heat sources and others as heat consumers. It 


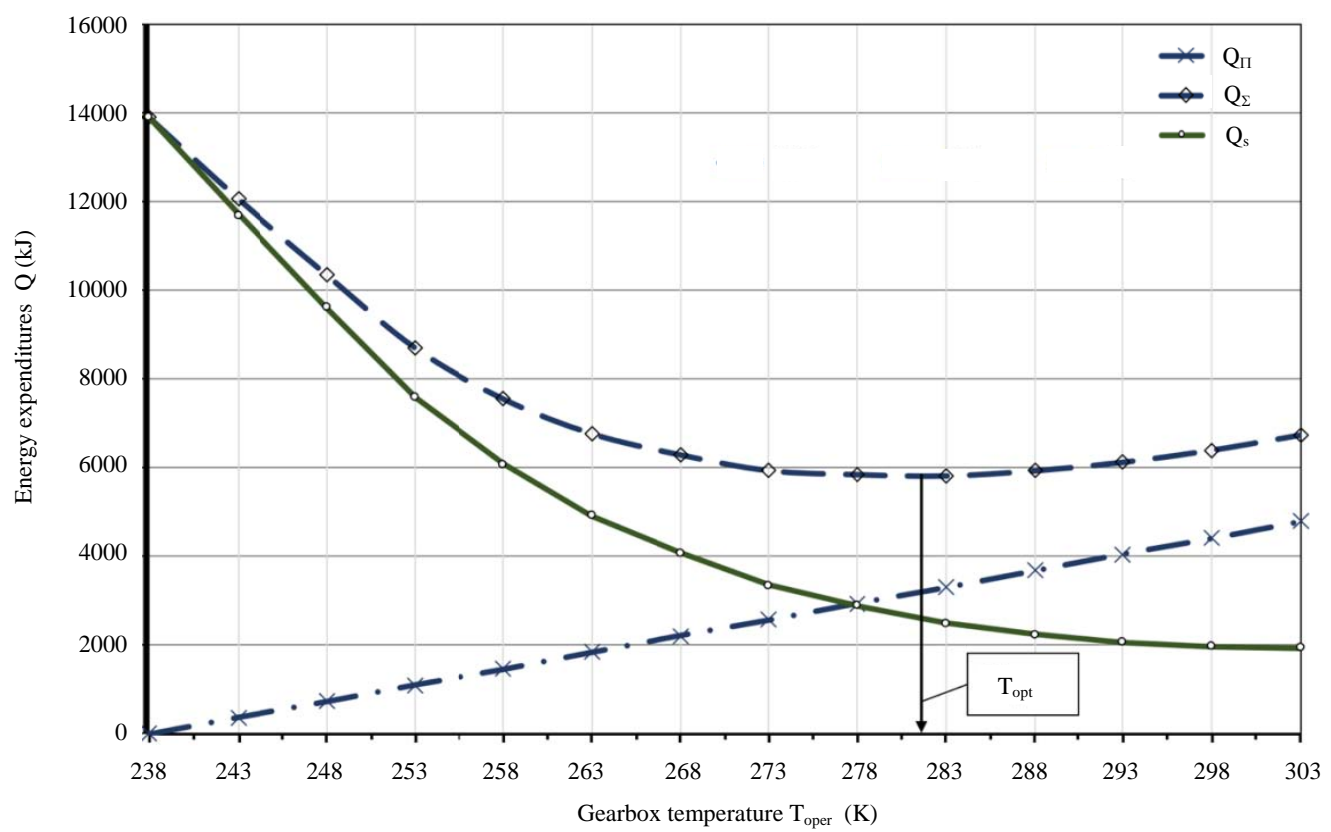

Fig. 5: Functional dependencies of energy expenditures on the oil temperature

is necessary to study the nature and amount of heat interaction between transmission units both during movement and in the idle state.

Thus, the problem of improvement of energy consumption when using transmissions at low temperature should be solved in the following order:

- Determine stabilization temperatures of lubricant oils for units in question under given operation conditions

- Calculate optimum thermal conditions for specific units and to compare results with the stabilization temperature

- Calculate additional quantity of thermal energy to ensure optimum resource expenditures considering energy losses to heat interaction between units themselves and with the environment

- Determine the volume of distribution of excessive heat among heat-stressed units

- Select and design technologies to implement the results of performed studies

\section{CONCLUSION}

Improvement of operation efficiency of vehicle transmissions at low temperatures is possible via. justification and provision of optimum thermal conditions of specific units and transmission as a whole.

As a criterion, we suggest using total energy expenditures to ensure thermal conditions and overcome friction torque under given conditions. Minimum total resource expenditures correspond to optimum thermal conditions of the transmission unit.
The optimum temperature value for each transmission unit shall be compared with the stabilization temperature under given conditions. This will help to make a decision on methods and means to achieve optimum resource expenditures.

Approbation of the suggested method of resource expenditures optimization as exemplified by the transmission gearbox of a KAMAZ truck, shows that minimum resource expenditures are achieved at the oil temperature of 281-282 K. The stabilization temperature of the gearbox under given conditions is $287 \mathrm{~K}$ which suggests excessive thermal potential.

To ensure minimum resource expenditures, it is necessary to use technologies that would help transfer excessive thermal energy to other units or the environment.

\section{REFERENCES}

Alvarez, R. and M. Weilenmann, 2012. Effect of low ambient temperature on fuel consumption and pollutant and $\mathrm{CO}_{2}$ emissions of hybrid electric vehicles in real-world conditions. Fuel, 97: 119-124.

Anisimov, I., A. Ivanov, E. Chikishev, D. Chainikov and L. Reznik et al., 2017. Assessment of adaptability of natural gas vehicles by the constructive analogy method. Intl. J. Sustainable Dev. Plann., 12: 1006-1017.

Buzin, Y.M., 2011. Mechanical efficiency of a transportable vehicle. J. Mech. Eng., 6: 3-6. 
Chainikov, D., E. Chikishev, I. Anisimov and A. Gavaev, 2016. Influence of ambient temperature on the $\mathrm{CO}_{2}$ emitted with exhaust gases of gasoline vehicles. Proceedings of the 2016 7th International Scientific Practical Conference on Innovative Technologies in Engineering National Research Vol. 142, August 31-September 10, 2016, Tomsk Polytechnic University, Tomsk, Russia, pp: 1-7.

Dolgushin, A.A., A.F. Kurnosov, M.V. Vakulenko and D.A. Domnyshev, 2015. Study of thermal operation conditions of transmission units and suspension in winter. Sci. Techn. Achiev. AIC., 7: 82-84.

Frank, W., 2010. A novel exhaust heat recovery system to reduce fuel consumption. Proceedings of the World Automotive Congress on FISITA 2010, May 30-Jun 4, 2010, FISITA, London, England, pp: $1-10$.

Gillot, R., A. Picarelli and M. Dempsey, 2015. Predicting the effect of gearbox preconditioning on vehicle efficiency. Proceedings of the 11th International Conference on Modelica, September 21-23, 2015, Linkoping University, Linkoping, Sweden, ISBN:978-91-7685-955-1, pp: 135-141.

Hawley, J.G., C.D. Bannister, C.J. Brace, S. Akehurst and I. Pegg et al., 2010. The effect of engine and transmission oil viscometrics on vehicle fuel consumption. Proc. Inst. Mech. Eng. Part D. J. Automobile Eng., 224: 1213-1228.
Iliev, S. and H. Lohse-Busch, 2018. Energy efficiency benefits of active transmission warm-up under real-world operating conditions. Master Thesis, SAE International, Troy, Michigan.

Izmailov, A., 2007. Technologies and engineering solutions to improve AIC transport system efficiency. Master Thesis, Federal State Institution of Science, Moscow, Russia.

Korneyev, S., S. Pashukevich, R. Buravkin, A. Anopriyenkoand and N. Machehin, 2017. Effects of low temperatures on internal losses in transmission units. Omsk Sci. Rep., 5: 18-21.

Liebrecht, J., X. Si, B. Sauer and H. Schwarze, 2015. Investigation of drag and churning losses on tapered roller bearings. Strojniski Vestnik J. Mech. Eng., 61: 399-408.

Merkisz, J., I. Pielecha, J. Pielecha and M. Szukalski, 2011. Exhaust emission from combat vehicle engines during start and warm-up. Transp. Prob., 6: 121-126.

Reiter, M.S. and K.M. Kockelman, 2016. The problem of cold starts: A closer look at mobile source emissions levels. Transp. Res. Part D. Transp. Environ., 43: 123-132.

Wang, B., Z.J. Lu, X.B. Chen, P. Wang and W. Luo et al., 2015. Modeling and analysis of the dynamic efficiency of manual transmission/reducer. Intl. J. Automot. Technol., 16: 417-426.

Weilenmann, M., J.Y. Favez and R. Alvarez, 2009. Cold-start emissions of modern passenger cars at different low ambient temperatures and their evolution over vehicle legislation categories. Atmos. Environ., 43: 2419-2429. 